\title{
Patient Monitoring under an Ambient Intelligence Setting
}

\author{
Pedro Eduardo Gomes, Alberto Marques, Ângelo Costa, Paulo Novais and José
} Neves

\begin{abstract}
In recent years there has been a growing interest in developing Ambient Intelligence based systems in order to create smart environments for user and environmental monitoring. In fact, higher-level monitoring systems with vital information about the user and the environment around him/her represents an improvement of the quality of care provided. In this paper, we propose an architecture that implements a multi-agent user-profile based system for patient monitoring aimed to improve the assistance and health care provided. This system mixes logical based reasoning mechanisms with context-aware technologies. It is also presented a case based on a scenario developed at a major Portuguese healthcare institution.
\end{abstract}

Key words: Ambient Intelligence, eHealth, Patient Monitoring, Multi-Agent Systems, Logical Based Reasoning, RFID

\section{Ambient Intelligence}

Computer Science is a fairly new field of scientific research in the healthcare arena and, despite having emerged recently, it has gone through important transformations and improvements during the last years. These changes led to many interesting experiences, generating a high expectation on the possibility of producing and developing various technologies to improve the way the environment can interact with us. This possibility has been explored in an area called Ambient Intelligence (or AmI). The concept of AmI emerged in 1998 and the evolution of technology was

Pedro Eduardo Gomes, Ângelo Costa, Paulo Novais, José Neves

CCTC, Departamento de Informática, Universidade do Minho, Braga - Portugal, e-mail: p.eduardogomes@gmail.com, acosta@di.uminho.pt, pjon@di.uminho.pt, jneves@di.uminho.pt

Alberto Marques

Chairman of the Board of Directors - CHTS, Penafiel, Portugal, e-mail: josealbertomarques@gmail.com 
a predominant factor for this birth. The revolution in the 80 's led to the emergence of the computer as a tool for the masses that has enabled its generalization and its use in all sectors of the society. Furthermore, with the advent of microprocessor, the increasing of computing power is astonishing, being used embedded in objects we use daily such as home appliances, mobile phones, PDAs or GPS navigational systems [1,2]. A new question arises: What is Ambient Intelligence?

Ambient Intelligence emerges as a vision of the future information society which will combine computing, ubiquitous communication and user-friendly interfaces with support for interaction with humans. There are some clues for its classification and many of them reflect the expectations that arise around this new area, i.e. to be sensitive, adaptive, intelligent, transparent, ubiquitous and responsive. The AmI capacity of being transparent is well associated with the notion of ubiquitous computing. This was envisioned by Weiser [3] who stated that the "most profound technologies are those that disappear. They weave themselves into the fabric of everyday life until they are indistinguishable from it.". In the design and development of AmI, effective use of sensors is vital because they provide information that will be analysed by intelligent agents, that may enable them to perform appropriate actions $[4,5]$.

\subsection{Patient Monitoring}

The vision of Mark Weiser is closely associated with that of other authors, i.e. those that see it as new paradigm of computing, an ubiquitous one. Healthcare seems to be the domain where the development of ubiquitous systems is more needed, once one has to make decisions based on factual information when needed. Therefore, it is considered that the health care sector represents a window of opportunity for the creation and implementation of this kind of systems. Given the current needs in terms of health care is essential to develop new support systems that are able to create safe and adaptive environments in order to satisfy the needs of each patient. It is felt that in the future, all healthcare institutions will be equipped with systems capable of interacting with the environment [2].

\section{Ambient Assisted Living in Healthcare}

In the recent years, many proposals of intelligent monitoring systems have been implemented. One of the projects described is AMADE, a multi-agent architecture that enables the control and supervision of home care environments. This incorporates intelligent agents, identification and localization technologies, wireless networks and mobile devices. This provides mechanisms for access through mobile phones or PDAs that connect to the system through wireless networks. It has alarms triggered by a notification management module and notifications that are sent trough SMS 
Gomes P.E., Marques A., Costa A., Novais P., Neves J., Patient Monitoring under Ambient Intelligence Setting, in Ambient Intelligence, Future Trends - International Symposium on Ambient Intelligence (ISAml 2010), Augusto JC., Corchado JM, Novais P., Analide C. (Eds.), Springer - Series Advances in Intelligent and Soft Computing, vol. 72, ISBN 978-3-642-13267-4, pp 185-188, (International Symposium on Ambient Intelligence, Guimarães, Portugal, 16-18th June/2010 ), 2010.

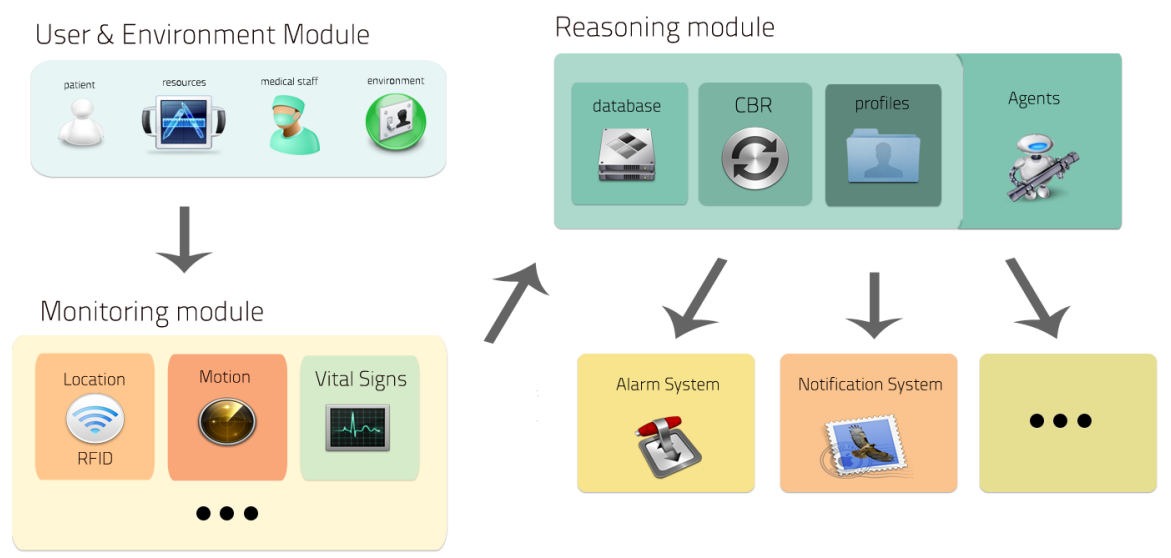

Fig. 1 The architecture for the monitoring system being proposed.

and MMS. The identification of users and their location is provided by the use of technologies based on Java Card and RFID [6]. The Java Card technology provides a secure environment for running applications on smart cards and RFID refers to a method of radio frequency identification through the use of labels (tags) attached to a person or object [7]. Another example is the system called ALZ-MAS [8], a multiagent system design to improve care for the elderly, especially those suffering from Alzheimer's disease. This system is based on a technology called FUSION (Flexible and User Services Oriented Multi-Agent Architecture) [9]. This proposes to facilitate and optimize the development of AmI systems through the integration of intelligent agents with Service-Oriented Architecture (SOA). In addition, this system uses several context-aware technologies that allow the access to information from users and the environment. In parallel to the project being described, it was developed another one called AGALZ (Autonomous monitoring aGent for ALZheimer's patients) which aims the development of deliberative agents using algorithms of Case-Base Reasoning as a way to implement a sensitive and adaptive system [10]. The EMon (Embodied Monitoring) project proposes a device attached to a patient, which collects information about him/her and the surrounding environment. This device is especially designed for monitoring the elderly people. In this project, it's presented a first prototype of this device that is capable of measuring environmental parameters like temperature and luminosity that allows the determination of the exact location of each patient through the use of a GPS module [11], being at the same time not invasive. 
Gomes P.E., Marques A., Costa A., Novais P., Neves J., Patient Monitoring under Ambient Intelligence Setting, in Ambient Intelligence, Future Trends - International Symposium on Ambient Intelligence (ISAml 2010), Augusto JC., Corchado JM, Novais P., Analide C. (Eds.), Springer - Series Advances in Intelligent and Soft Computing, vol. 72, ISBN 978-3-642-13267-4, pp 185-188, (International Symposium on Ambient Intelligence, Guimarães, Portugal, 16-18th June/2010 ), 2010.

\section{An Ambient Intelligence based Architecture for Patient Monitoring}

This is a system that aims to ensure a continuous and effective monitoring of patient treatment by specialized staff and equipment in any healthcare facility, allowing for the precise location of a specific position or point in physical space, either in terms of professionals or equipment resources [11]. It is a multi-agent that includes reasoning mechanisms and context-aware technologies for monitoring patients, healthcare professionals, physical resources and the environment that surrounds them. Due to its modular design can be integrated with other systems existing in the hospital, like alarms, management or notification systems, among others. The proposed architecture is built on 3 (three) different modules, as it is depicted in Figure 1:

- User \& Environment module: This module refers to the patients and the entire environment that surrounds him/her. It is related to a high level monitoring of patients, health professionals and resources. The information obtained makes the input data of the entire system;

- Monitoring Module: The monitoring module intends to guarantee an effective monitoring through the use of diverse sensors and context-aware technologies. The location of patients, resources and medical personnel can be assured through the use of RFID sensors. It would be also possible to measure the atmospheric conditions present in each area (e.g. temperature, humidity levels, the concentration of $\mathrm{O}_{2}$ ) or to measure the vital signs of each patient; and

- Reasoning Module: The main function of this module is to perform actions according to the conditions verified and it is responsible for managing the information gathered through the previous modules. The system includes reasoning mechanisms brought by the integration of an Case Based Reasoning (CBR) module. Thus and so, when the system is faced with a new situation it will search for similar cases in the knowledge base. Upon selection of the closest case, it may happen that the cases are too similar and the system will subscribe the action performed, or the cases are so different that this new situation is considered to be a new case. This module also includes the different profiles of the possible users. Patients, doctors, nurses or visitors are clearly identified so the system can determine who and where each user is. This feature aims to improve the security and the quality of healthcare services by enhancing the monitoring acuity.

To better understand the functioning of this system in a healthcare institution, consider the case of a healthcare unit that implements the architecture referred to above. All patients, healthcare professionals and the resources are monitored and fully traceable through the use of RFID tags. Imagine that a patient moves from one room to one another. This event triggers a notification to the doctor(s) that is(are) responsible for his/her condition, sending them its geographic coordinates. When the patient returns to his/her previous location, the system will send another message to warn about the new situation. The same principle is applied to the resources when they are being used or have been transferred to other units. Monitoring of the hospital environment is also crucial to ensure the necessary balance. For example, 
by using motion detectors, it is possible to detect the presence of foreign elements which may be harmful to the patients or professionals. With the implementation of different profiles of identification, the system could distinguish whether it is a patient, a doctor, a nurse or even a person who wants to visit any of these actors. It is allowed different levels of permissions on each of the different spaces. Suppose that a given patient is hospitalized in critical condition and that only doctors and nurses can enter the room where he/she is admitted. If it detects a foreign user or an unauthorized profile, it sends notification to the alarm system that will take the actions needed to stop this threat. Every new situation will increase the number of cases to be used by the reasoning module that may help to increase the level of efficiency of the system. These were some examples of the operational framework. However, due to its characteristics, they may be adapted to different contexts and communicate with systems with different features.

\section{The Architecture}

As seen before, the system proposed must, first of all, be able to accept and integrate a very heterogeneous group of devices and technologies. This means that the architecture to be considered must provide the means for these components to coexist and work together. It is therefore mandatory that the architecture will provide a communication and information mechanism where all different components can make a profit on how communication is a key factor in cooperative systems. The architecture must also integrate very different devices or components and provide means for their intercommunication. It should be dynamic and expansible, ready to accept new functionalities and new devices. To ensure this, it will be used two different service-oriented standards: OSGi and WebServices. The OSGi [5] Service Platform is a Java-based application server for networked devices, ranging from computers or mainframes to mobile phones or other hand-held devices, which means it can be deployed to any platform running the Java Virtual Machine. The resulting modules are called bundles, which can provide not only services but also to use services provided by other bundles. In OSGi, a bundle can be installed, started, stopped or un-installed at run-time and without any kind of system reboot, which makes OSGibased technologies very modular and dynamic. Since in AmI there are multiple entities communicating with one another, providing and requesting services, it is easy to understand the interest in using such technology. Web Services can be seen simplistically as a way of sharing information over a network. Each component that provides information declares Web Services that are then requested by the other components that need to access that information. Under this computational framework, we gain interoperability and platform independence. This means that the system proposed can be used by any other higher level architecture and use services provided by that architecture, therefore implementing a system of sharing services and possible improvements. It also results in a very expansible architecture as it is easy to add new components, which does not affect the components already present. 
Gomes P.E., Marques A., Costa A., Novais P., Neves J., Patient Monitoring under Ambient Intelligence Setting, in Ambient Intelligence, Future Trends - International Symposium on Ambient Intelligence (ISAml 2010), Augusto JC., Corchado JM, Novais P., Analide C. (Eds.), Springer - Series Advances in Intelligent and Soft Computing, vol. 72, ISBN 978-3-642-13267-4, pp 185-188, (International Symposium on Ambient Intelligence, Guimarães, Portugal, 16-18th June/2010 ), 2010.

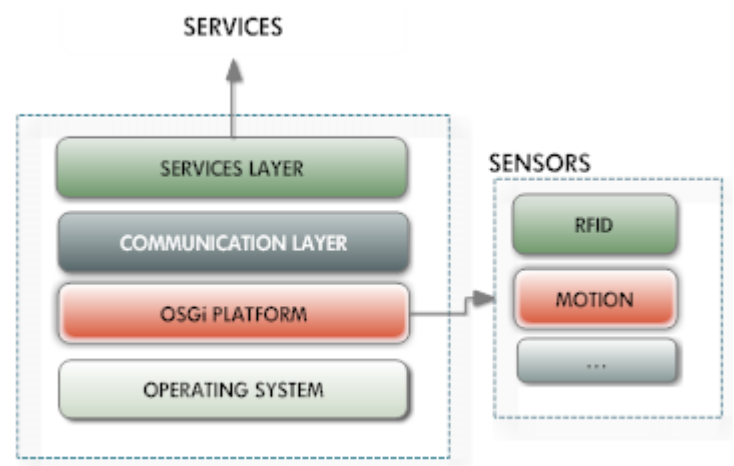

Fig. 2 The communication architecture.

\section{An Implementation in a Real Environment}

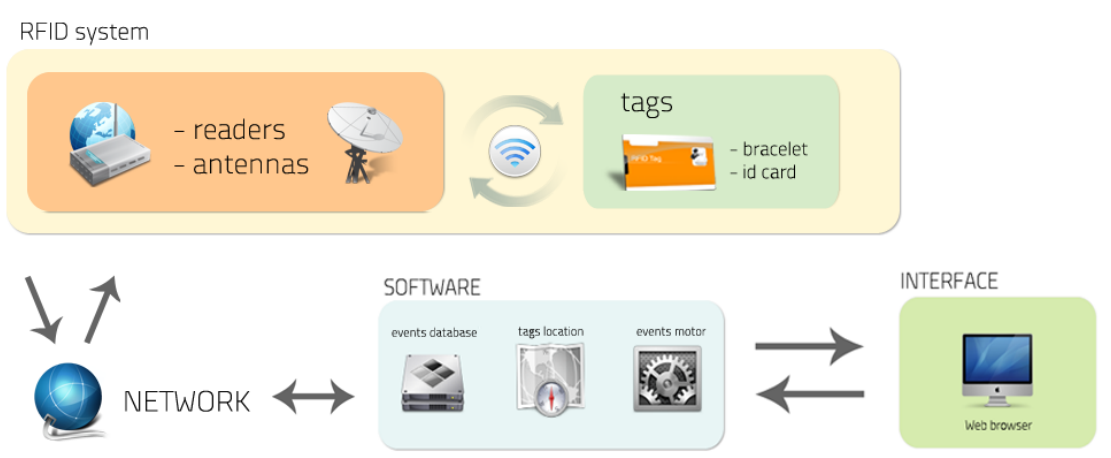

Fig. 3 An overview of the system implemented in CHTS - E.P.E.

Thefts of newborns are not a rare phenomenon and the number of new cases rises every year. From 1983 to 2008, 267 newborn infants were abducted from U.S. hospitals, according to data from the National Center for Missing and Exploited Children [13]. This is a scourge that must be tackled with the adoption of measures where safety is the keyword. Therefore the implementation of an AmI system that allows a constant and continuous monitoring of newborns may be a valid solution. Aware of this, the administration of the Centro Hospitalar do Tâmega e Sousa, E.P.E. (CHTS) enforced procedures to guarantee the safety of newborns, one measure being the implementation of an RFID based location system. To each newborn it is attached an RFID bracelet that allows their identification and location. After that, the tag becomes active and it is registered a new entry in the system, associating all the newborn's information with the tag. On the other hand each doctor, nurse or 
visitor has an identification card with RFID tags. So, it could be known who enters or leaves the nursery, at any time. All the events are registered to a database, which allows for a complete record of all activities being carried on.

This location system can be adapted to fit into the architecture features that are being proposed in this work. By the application of logic based reasoning mechanisms to the data obtained and stored, and using a model of the different user profiles, the security and monitoring efficiency may be enhanced. In this way, the alert level would be different if a doctor or nurse picks up a newborn and leaves the nursery from that of any other person that does the same. As more situations arises, the e-learning module has more cases to consider, therefore enhancing the ability of the system to react to unexpected situations.
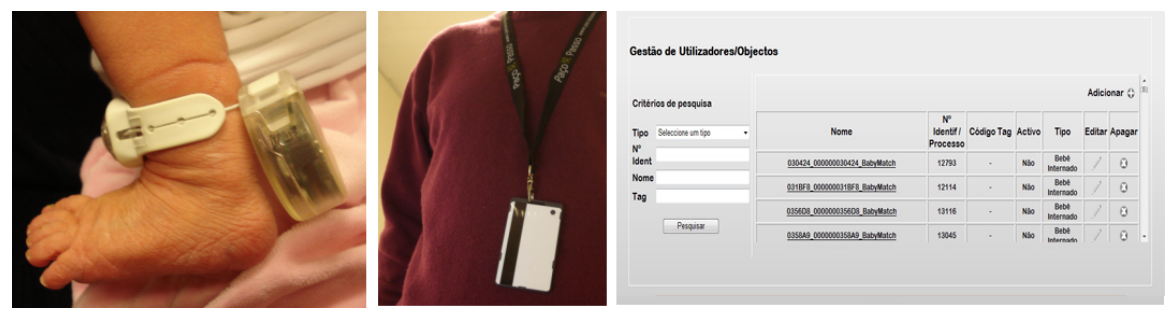

Fig. 4 a) An RFID bracelet attached to a newborn feet b) An RFID Card for the hospital employees c) Screen-shot of the application control and management of newborns RFID tags.

In this healthcare facility all the services reported to the same entity, a computational framework called AIDA (an Agency for the Integration, Diffusion and Archive of information). It enables the interoperation between the existing systems and applications by using SOA (Subjective, Objective Assessment planning). The communication is established thought normalized protocols (like HL7), i.e. AIDA caters for a safe, flexible and efficient environment for access, record and diffusion of clinical data in a real environment, on time. As represented in Figure 4, the reasoning module proposed communicates with AIDA, and then may interact with other systems or simply using the information directly received. Using this modular approach has numerous advantages because it allows for other systems to be integrated into an existing structure without affecting it.

\section{Conclusions}

In this paper it was presented a logic based framework for patient monitoring. It includes context-aware technologies that associated to knowledge representation and reasoning mechanisms (e.g. CBR) aims to create a safe, adaptable environment where patients, doctors and resources may be monitored at any time. With the utilization of open-standards of communication like OSGi and WebServices, the system may be expansible and easily integrated with other ones, which represents a 
Gomes P.E., Marques A., Costa A., Novais P., Neves J., Patient Monitoring under Ambient Intelligence Setting, in Ambient Intelligence, Future Trends - International Symposium on Ambient Intelligence (ISAml 2010), Augusto JC., Corchado JM, Novais P., Analide C. (Eds.), Springer - Series Advances in Intelligent and Soft Computing, vol. 72, ISBN 978-3-642-13267-4, pp 185-188, (International Symposium on Ambient Intelligence, Guimarães, Portugal, 16-18th June/2010 ), 2010.

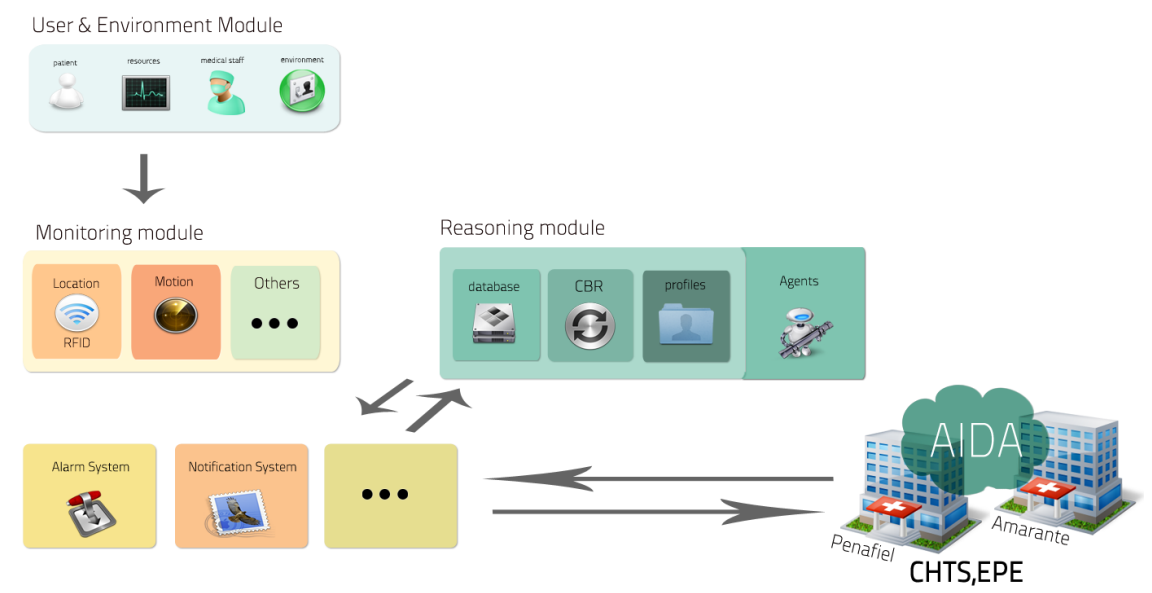

Fig. 5 Integration between the proposed system and the AIDA framework that runs in the CHTSE.P.E..

gain in interoperability. We just started the implementation of the architecture proposed on the nursery unit of the CHTS - E.P.E., Portugal.

\section{References}

1. D. J. Cook, J. C. Augusto, and V. R. Jakkula, "Ambient intelligence: Technologies, applications, and opportunities," Pervasive and Mobile Computing, vol. 5, 2009.

2. S. Sneha and U. Varshney, "Enabling ubiquitous patient monitoring: Model, decision protocols, opportunities and challenges," Decision Support Systems, vol. 46, no. 3, pp. 606 - 619, 2009. Wireless in the Healthcare.

3. M. Weiser, The Computer for the 21 Century. Scientific American, 1991.

4. A. Moreno and J. L. Nealon, Applications of Software Agent Technology in the Health Care Domain. Birkhauser (Architectural), 2004.

5. G. Lanzola, L. Gatti, S. Falasconi, and M. Stefanelli, "A framework for building cooperative software agents in medical applications," Artificial Intelligence in Medicine, vol. 16, no. 3, pp. 223-249, 1999.

6. L. Byunggil and K. Howon, "Ubiquitous rfid based medical application and the security architecture in smart hospitals," in ICCIT '07: Proceedings of the 2007 International Conference on Convergence Information Technology, (Washington, DC, USA), pp. 2359-2362, IEEE Computer Society, 2007.

7. J. A. Fraile, J. Bajo, and J. M. C. Rodríguez, "Multi-agent architecture for dependent environments. providing solutions for home care.," Inteligencia Artificial. Special Issue 7th IberoAmerican Workshop in Multi-Agent Systems (Iberagents 2008), vol. 42, 2009.

8. Óscar García, D. I. Tapia, A. Saavedra, R. S. Alonso, and I. García, "Alz-mas 2.0; a distributed approach for alzheimer health care," 3rd Symposium of Ubiquitous Computing and Ambient Intelligence 2008, vol. 51, 2009.

9. D. I. Tapia, S. Rodríguez, J. Bajo, and J. M. Corchado, “Fusion@, a soa-based multi-agent architecture," in DCAI, pp. 99-107, 2008. 
Gomes P.E., Marques A., Costa A., Novais P., Neves J., Patient Monitoring under Ambient Intelligence Setting, in Ambient Intelligence, Future Trends - International Symposium on Ambient Intelligence (ISAml 2010), Augusto JC., Corchado JM, Novais P., Analide C. (Eds.), Springer - Series Advances in Intelligent and Soft Computing, vol. 72, ISBN 978-3-642-13267-4, pp 185-188, (International Symposium on Ambient Intelligence, Guimarães, Portugal, 16-18th June/2010 ), 2010.

10. J. M. Corchado, J. Bajo, Y. de Paz, and D. I. Tapia, "Intelligent environment for monitoring alzheimer patients, agent technology for health care," Decision Support Systems, vol. 44, no. 2, pp. 382-396, 2008.

11. D. Carneiro, P. Novais, R. Costa, P. Gomes, and J. Neves, "Emon: Embodied monitorization," in AmI '09: Proceedings of the European Conference on Ambient Intelligence, (Berlin, Heidelberg), pp. 133-142, Springer-Verlag, 2009. 